\title{
From Start to Finish: Teenagers on the Autism Spectrum Developing their Own Collaborative Game
}

\author{
Benoît Bossavit \& Sarah Parsons
}

\begin{abstract}
Purpose: This study investigates how teenagers on the autism spectrum respond to their involvement in the creation of a collaborative game, meeting the curriculum requirements in programming at secondary level in England.
\end{abstract}

Design/methodology/approach: Two autistic teenagers were involved in participatory design processes to elaborate and develop together a collaborative game of their choice using the visual programming software, Kodu Game Lab.

Findings: With the support of adults (teachers and the researcher), the participants were able to demonstrate and strengthen their participation, problem-solving and programming skills. The participants expressed their preferences through their attitudes towards the tasks. They created a game where the players do not need to initiate any interaction between each other to complete a level. Furthermore, the students naturally decided to work separately and interacted more with the adults than with each other.

Research limitations: This is a small case study and so cannot be generalized. However, it can serve as starting point for further studies that involve students with autism in the development of interactive games. 
Practical implications: It has been shown that disengaged students can develop various skills through their involvement in software programming.

Originality/value: Overall, this paper presents the involvement of teenagers on the autism spectrum in the initial design and development of a collaborative game with an approach that shaped, and was shaped by, the students' interests. Although collaboration was emphasised in the intended learning outcomes for the game, as well as through the design process, this proved difficult to achieve in practice suggesting that students with autism may require stronger scaffolding to engage in collaborative learning.

\section{Keywords}

Game design; Collaborative game; Autism; Kodu; Student voice; participatory design 


\section{Introduction}

Autism Spectrum Disorder (ASD) is formally defined by pervasive difficulties in communication and social interaction usually combined with repetitive and stereotyped behaviours (American Psychiatric Association, 2013) ${ }^{1}$. The use of technology is recognized for supporting learning for children and teenagers on the autism spectrum, particularly in the core areas of social interaction and communication (e.g. Chen, 2012; Wass and Porayska-Pomsta, 2014). For example, video games show positive demonstrations of collaborative strategies which increase the awareness towards the other player when active participation is required (Silva et al., 2015). Alongside the development and evaluation of specific technologies for supporting particular skills or understanding, there is growing awareness of the importance of participatory design approaches in technology development, especially for children and teenagers (e.g. Nouwen et al., 2016; Parsons et al., 2011). Such approaches recognise the value of including representatives from 'end user' or stakeholder groups in design in order to provide more appropriate and effective technological applications. As Druin (2002; p.1) suggests, children's direct involvement in the design of educational games is important because:

'Children have their own likes, dislikes, curiosities, and needs that are not the same as their parents or teachers. As obvious as this may seem, we as designers of new technologies for children, sometimes forget that young people are not "just

\footnotetext{
${ }^{1}$ The language used to describe people with ASD is a contended area with different people having different views, such '...that there is no single way of describing autism that is universally accepted and preferred' (Kenny et al., 2016; p.442). Nevertheless, 'autism' and 'on the autism spectrum' were highly endorsed terms in Kenny et al.'s (2016) study and so this is the language we will use in reference to our own study. When describing the work of others we will use the terminology published in their papers.
} 
short adults" but an entirely different user population with their own culture, norms, and complexities'.

Reflecting the value of soliciting these unique perspectives, some children on the autism spectrum (aged 7-13 years) have been involved in the design of educational games (Benton and Johnson, 2015) with the aim of increasing their engagement, as well as their academic and collaborative skills (Guha et al., 2013; Parsons et al., 2011). Children (aged 12-13 years) with high functioning autism have provided creative ideas and collaborated with other stakeholders through the use of sophisticated tools such as visual schedules or screenshots of the game prototype to sketch improvements (Benton et al., 2012). Nevertheless, a study with children and teenagers (aged 8-14 years) showed that difficulties might be encountered in giving voice in design processes since the participants can feel frustrated when the output differed from what they had imagined (Parsons and Cobb, 2014). In these previous projects, children and teenagers were involved in making design decisions on technology ideas that were initiated by the researchers rather than by themselves and were also not responsible for implementing design changes or directly developing the game. Consequently, the children's roles, though important, remained somewhat limited and adults remained in charge of the decision-making. We wanted to explore the process and outcomes if we involved teenagers on the autism spectrum at earlier stages of the design process, and involved them more as design 'partners' rather than as 'testers' or 'informants' (using Druin's, 2002, terminology).

Therefore, we extended the area of enquiry of participatory design by involving teenagers on the autism spectrum with good language skills in the initial design and development of a collaborative game. An educational game aims to improve specific skills by using some properties of video games such as storylines or rewards, to achieve benefits for learning (Kapp, 2012). It has been shown that involving children and teenagers (aged 10- 
14 years) in the development of educational games is promising and shows increased engagement, problem-solving and programming skills (Akcaoglu, 2014; Hwang et al., 2014; Ke, 2014). However, these studies involved typically developing children only and so may not offer appropriate content, or insights into how to structure the development process for the specific learning and support needs of children on the autism spectrum (Ploog et al., 2013), which may differ substantially from typically developing children (Jordan, 2005).

Moreover, there is wider relevance and impetus for developing children and teenagers' programming skills in the UK, at least in England. Since 2013, the National Curriculum in England recognizes the need for programming skills being taught in schools at primary and secondary levels to meet the skills requirements of a knowledge economy (National Curriculum in England, 2013). There are few examples in the literature, as yet, regarding how such programming skills have been supported via specific programming tools and, specifically, from the perspective of students on the autism spectrum within school settings. Consequently, the first main aim of the study was to investigate how teenagers on the autism spectrum would respond to their involvement in a design process for an interactive game, as part of meeting the curriculum requirements in programming at secondary (high school) level.

There are several visual programming software programs especially designed for children, such as Scratch and Stagecast Creator. Both have been evaluated by groups of typically developing children (aged 10-12 years), with positive indications for attitudes and enjoyment (Baytak and Land, 2011; Ke, 2014). However, Denner et al., (2012) highlighted the need for proper guidance and instructional support to maintain high levels of engagement by the pupils. Another common game development tool especially designed for children is Kodu Game Lab. Kodu differs from other tools by enabling 
children to develop 3D environments. Furthermore, Kodu is less focused on advanced programming syntaxes and includes specific tools for level editing and so, potentially, might be more accessible and engaging because it is easier to use and understand (Fristoe et al., 2011). Typically developing children (aged 11-13 years) who were asked to create their own game, as well as to review peers' games, reported improvements with in-depth thinking, creativity and motivation (Hwang et al., 2014). Thus, in this study we decided to use Kodu since it integrates more features of level edition including dynamic interaction with the 3D environment. Furthermore, we could observe whether, and how, the participants could use the Kodu programming tool successfully in their classroom environment.

We specifically structured the design process and objectives around the idea of collaboration since we know that while children and teenagers on the autism spectrum may struggle with, or avoid, some activities requiring collaborative interactions they can, nevertheless, engage successfully if tasks are appropriately structured (Parsons, 2015). In this project, collaboration was both the means and the outcome of the design and development of the interactive game. That is, the students were tasked with creating a video game that required collaboration with others to complete it, while at the same time collaborating with others in order to develop, discuss, and agree their plans. In other words, collaboration was both an explicit educational goal of the game, and an implicit part of the game development process. Below we first describe the design process, then we analyse the sessions that took place, which allows some reflection on how the design process shaped the teenagers' interests, as well as the relationship between the stakeholders (students, teachers, and the researcher). We were particularly interested in how, and by whom, different decisions would be made and deliberately began without a prescriptive plan in order to enable participation to emerge and develop. 


\section{Design Process}

\section{Participants}

The project involved two 15-year-old males, on the autism spectrum and with good language skills: Jack and Nathan (pseudonyms). Involvement of the students was decided by the teachers at the school, who also confirmed diagnostic details. Jack and Nathan attended a specialist school for students with special educational needs in the UK. Both teenagers had histories of disengagement from school, though were doing well now and keen to be involved in the project. For each session, the ICT teacher and the researcher (first author) were present to guide and help the design and development of the game. Informed consent from parents / carers was obtained prior to the study as well as assent from the students. The project received ethics review and approval from the University of Southampton (ref \# 15387).

\section{Sessions}

Previous participatory design approaches with children with autism have tended to base the content of their design sessions on specific educational approaches such as TEACCH or SCERTS (Benton et al., 2012; Frauenberger et al., 2011; Millen et al., 2011). Although the design of the game was an important aspect of this study, the core focus was on the programming part and so our approach was more exploratory. Specifically, we drew upon the good practices identified in Bossavit and Parsons (2016), who adopted a flexible design approach with teenagers on the autism spectrum. For instance, the adults in that study ensured the teenagers' well-being by encouraging and guiding them, and let the participants adopt a specific role (user, co-designer...) regarding the objective of the current session, and their individual preferences. 
Regarding the game development, we were inspired by the work of Akcaoglu (2014) and Hwang et al., (2014), and classified our approach into four stages: (i) a learning stage where the students could learn about the programming environment; (ii) a design phase where the teenagers could define the features of the game; (iii) the development step where the participants could program the features, and (iv) a level design part where they could define a final scenario that integrates their work.

The teenagers were involved in nine sessions over 3-4 weeks. The length of the sessions varied from 30 minutes to 1 hour, depending on the motivation of the participants. Both teenagers could not attend all the sessions due to timetable clashes. The sessions are described next according to the four stages noted above.

Stage 1-Introduction to Kodu (2 sessions: 1h20): The objective was to introduce students to the environment and teach them the basics of programming. Jack and Nathan were shown technical demonstrations of Kodu such as 'questions-and-answer' or 'world exploration' in order to give an overview of the system. Then, they followed tutorials and specific exercises such as implementing a dialogue between two virtual characters. Both the ICT teacher and the researcher guided the students in the implementation of the tasks.

Stage 2 - Game design (1 session: Oh30): Jack and Nathan knew that they were going to develop, alongside their teacher and the researcher, a game of their choice, and that the game should focus on collaboration between two players. Thus, the objective of this session was to decide the context and the content of the game. The researcher played the role of facilitator guiding the conversation with open questions such as "what type of game would you like to develop?" or guided ones such as "Do you think the characters should have the same characteristics?" Therefore, the scenario was designed incrementally through appropriate questioning. 
Nathan once checked on the internet for other collaborative games before deciding that the characters should behave differently from each other. Then he wrote down their respective features: one would be a warrior more resistant to damage who would be equipped with weapons, and the other one would create and manipulate elements such as a big rock that can be used as a shield. Jack sketched a scenario that highlighted the role of each player (Figure 1).

***Include Figure 1 about here***

Stage 3 - Development (4 sessions 3h45): The objective in these sessions was to implement the characters that would be required later in the design of the levels. Jack wanted to work on the warrior while Nathan worked on the other character. Consequently, we organized two teams: Jack with the ICT teacher and Nathan with the researcher. The adults were co-developers and were also in charge of guiding and explaining new concepts, as summarised in Figure 2.

***Include Figure 2 about here***

Stage 4 -Level-design (2 sessions: 1h10): The objective was to generate a level in which players must collaborate to complete it. Jack could not attend the last two sessions, consequently Nathan designed the first level which was a tutorial. He commented that the level should be shaped like a spiral (Figure 3). Each part of the spiral represents a different enigma that players would solve during the whole game. The level design raised issues that forced Nathan to change the code. For instance, the warrior, which was a flying 
object, could go beyond the limit of the map. Consequently, Nathan decided to change the warrior to a non-flying object so that they had to stay within the boundaries of the map.

***Include Figure 3 about here $* * *$

\section{The Game}

The objective was to reach the end of the game by resolving puzzles together. Jack designed the warrior character with particular powers that could help him overcome opponents. Jack also designed three opponents (a cannon, a star, a tower) which created specific challenges for both characters. As a result, the warrior was in charge of the protection of the other player. Furthermore, collaboration between the characters was also achieved by special powers, for example Nathan's character could create an igneous stone that reduces the level of lava flow so that the players would be able to cross it.

\section{Findings}

Engaging teenagers in activities is essential especially for those who have experienced exclusion and disengagement from school. Students were involved from the beginning of the project (Parsons and Cobb, 2014), and empowered within different roles (Benton and Johnson, 2015) across different stages of development, such as game designer, developer and level designer. All the information used for this analysis is based on the observation notes that the lead researcher wrote down during and after each session.

In order to understand the participation of the teenagers' in the design process, we mapped each of our sessions to existing participatory design frameworks (Benton and Johnson, 
2015; Bratteteig and Wagner, 2012). These frameworks enable us to illustrate the specific contributions of each participant, how this changed over the sessions, and who made decisions at different stages of the design process. This mapping is shown in Table 1. The categories from Benton and Johnson (2015) focus on the role of the user, how their participation was supported, and the tools used to support their participation. In other words, the who and how of the design process. In terms of roles (the who), Benton and Johnson (2015) describe these as:

- User - observed using an established technology;

- Designer - actively contributes to design decisions;

- Facilitator - provides information and resources necessary;

- Co-designer - guides idea generation and inspiration;

- Developer - programs game features;

- Co-developer - guides code generation.

With regard to participation (the how), Benton and Johnson (2015) describe two main categories: (1) Dialogue, which refers to verbal exchanges with the other stakeholders; and (2) Feedback, which is either verbal or behavioural communication related to the objective of the session without any exchange. The tools used are open-ended and so simply describe how the engagement of the students was supported at each stage of the design process. Bratteteig and Wagner's (2012) categories provide a useful extension of Benton and Johnson's (2015) because they provide information about the what of the design process (i.e. the aspects that different stakeholders are making decision about), in addition to the who and how. Specifically, Bratteteig and Wagner (2012) focus on delineating the nature of the decision made through the design process and about which aspects each participant made decisions. Their category of 'values and concepts' refers to 
decisions on ethical and pedagogical aspects of the game design, whereas 'implementation' relates to decisions on the technical design content.

$$
\text { *** Include Table } 1 \text { about here*** }
$$

\section{Engagement}

Drawing on the frameworks of Benton and Johnson (2015) and Bratteteig and Wagner (2012) summarised above, we grouped the stakeholders' behaviour (communication and actions) into three categories in order to define their overall engagement: (1) the participation in the design process, (2) the achievement of the tasks, and (3) the roles and decisions undertaken during the design sessions (see Table 1).

\section{Level of participation}

We observed that the teenagers' participation differed from each other across the sessions. During the introduction sessions, Jack spent more time on the level design whereas Nathan focused on the characters' controls. This gave insights that Nathan and Jack did not have the same interests and they tended to spend more time on the aspects that they preferred. This is a common behaviour that had already been observed in previous projects involving typically developing children (Ke, 2014; Vos et al., 2011). During the design sessions, both students participated actively, Nathan did some research on the internet to decide about the characters' features and Jack sketched a scenario to illustrate his ideas. Narration through stories can, indeed, enable personal expression (Kafai, 2006). The development sessions showed that the particular interests of the participants influenced their levels of engagement. Jack showed a minimum level of participation. First, he did not communicate much with his teacher and mostly followed the teacher's instructions. Second, when the ICT teacher had left the room during one of the sessions, 
Jack exited Kodu to watch videos on the internet. The lead researcher tended to re-engage Jack by asking whether he had finished programming his character and Jack answered (ironically) that he had decided to make it totally invisible! It is important to note that the session took place during the ICT lesson and the role of the teacher remains central in the engagement of students (Dykstra Steinbrenner and Watson, 2015).

Nevertheless, although Jack did not want to participate in solving code integration issues, he patiently waited for Nathan to solve it so that he could share his character's settings. This shows that even though the programming part was not motivating for Jack, he remained interested by anticipating the result of the final outcome. On the other hand, Nathan was concentrated and involved the lead researcher verbally in the programming. At the end of the second session of programming, the ICT teacher commented that he had been really surprised by Nathan's level of participation since Nathan had a very bad week at home and did not participate in his other classes. This illustrates that one of the advantages of game design learning is the range of activities it can promote, thereby enabling flexibility in supporting individual preferences.

\section{Task achievement}

Regarding academic skills, this study was motivated by developing programming and problem-solving skills. Therefore, the different stages promoted the students to learn these new skills which also supported their engagement. For instance, during the development stage, Nathan had learnt abstract concepts such as creatables, which is a special mechanism to clone intelligent objects without duplicating the associated programming code, or code indentation, which is important for applying specific behaviours under certain conditions. To reach such a level, he had to deal with several programming challenges and develop specific abilities to solve them. He solved these 
problems via deeper research on the internet, by asking the researcher directly, or via a "trial-and-error" approach (Gee, 2003) in order to get direct feedback and improve his code. Jack's approach was different since he lacked the initiative during the development phase. Indeed, Jack was mostly waiting for his teacher's instructions. This correlates with his lower level of participation when it came to technical aspects of the project. However, Jack also adopted a "trial-and-error" approach in order to optimize the features of his character. Overall, as well as learning specific programming skills, the students learned to problem-solve either by their own or with the help of the adults. Thus, they overcame their own gaps in knowledge and skills in order to carry out the prototype; albeit in different ways, they persevered with the task.

\section{Stakeholders' role:}

We adopted an informal approach to the design process within which the teenagers were provided with responsibilities to maintain a high level of challenge. They made decisions about the content of the game, from the general objective to the features of the characters, as long as it involved two players in a cooperative scenario. Elaborating ideas usually requires a clear starting reference (Benton and Johnson, 2014; Parsons and Cobb, 2014). Thus, the aim of the introduction to Kodu was to provide information about capacities and limitations of the software so that the teenagers could design the game taking into account these technical aspects. Indeed, the teenagers obtained an overview of the functionalities (objects that they could create as well as the behaviour of the virtual characters within the environment), which helped later in the design of a technically feasible scenario. Thus, the role of facilitator undertaken by the adults was crucial in providing a general idea to the teenagers of the extent of Kodu through guided exercises. Once the teenagers had undertaken the role of designer (Druin, 2002) they quickly took decisions on values and concepts (Bratteteig and Wagner, 2012) and sometimes rejected 
ideas proposed by the adults. For instance, the lead researcher proposed a camouflage mode for the warrior so that enemies could not see the player during a period of time and Jack commented that he did not like the idea. He, afterwards, took a sheet of paper and sketched the scenario he had in mind. This illustrates that, through a programming and design process that respected and valued their ideas, students were supported to be relatively independent and autonomous learners. Indeed, they did use, on their own, specific tools such as internet searches or sheets of paper to sketch their ideas (see Table 1).

Furthermore, the students could decide the key aspects of the future outcome of the game. Although most of the important decisions were set during the game-design stage, the development stage also required concrete implementation-based decisions which had to be made, especially during the integration of the code and the design level sessions. This is an important point because by working on different aspects of the game the teenagers had raised issues which increased the challenge. Therefore, they spent longer being engaged with the task, showing perseverance and further development of their skills and understanding through the natural unfolding and implementation of their ideas. Again, because the students' ideas were central to the game development, they were heavily invested in seeing the process through to the end, even when the requirements for their own learning and engagement became much more challenging.

\section{Collaboration strategies}

\section{Design process}

The students naturally decided to work separately and interacted more with the adults, who also played an important role in these student-focused participatory design approaches (Benton and Johnson, 2015). It is important to highlight that even though the 
roles might look similar amongst the students, their attitudes towards the tasks differed according to their core interests. During the development stage, although all the stakeholders (students, teachers, and researcher) were co-developers, the interaction from one team to the other was very different: Jack mainly executed the advice given by the teacher while Nathan involved the researcher in the programming asking for alternative solutions. Consequently, the role of the adults, apart from facilitating and supporting the students to keep the attentional level high, was to adapt the sessions to the needs and interests of the students to support their continued engagement and participation.

\section{Game content}

In terms of the game design, collaboration was a tricky concept for the students to include but there was evidence that they tried to meet this objective. Giusti et al. (2011) defined four collaborative patterns in games: choosing together, constraints on objects, different role, and ownership [of different objects]. In this study, the teenagers (spontaneously) decided to employ two out of these four patterns. The first one is about different role where each player owns a character with different features. The second collaborative pattern, constraints on objects, is a direct consequence of the first one since the players interact differently with the environment according to their properties. Indeed, one player has constraints on enemies due to its lack of weapons and poor defence capacities and the warrior has constraints on the objects of environment. Nevertheless, it is noteworthy that the elements of collaboration that the students included were related to features of the environment, rather than supporting the players of the game to communicate or collaborate with each other, thereby opportunities for interaction in the game were very limited. Other collaboration or communication features may well have been integrated in the game given sufficient time (and scaffolding of the idea) but it was not possible to spend longer in the school to continue further with the project. 
Therefore, the prototype reveals that the players do not need to initiate any interaction between each other to complete a level. Although both players are needed in order to play the game and should synchronise, the characters were designed in a way that they just need to interact with the environment. In other words, the teenagers designed a game where social interaction is rather limited. Social interaction between the teenagers was also limited during the design sessions where they hardly interacted with each other and preferred teaming up with the adults. All this might be a reflection of specific social issues which are experienced by individuals with autism, although more participants and prototypes would better shed light on such a phenomenon.

\section{Discussion and conclusions}

We involved teenagers on the autism spectrum with good language skills and a history of school disengagement in the design and development of a collaborative game over a number of weeks. Key skills and concepts were embedded in the design process of the game, namely: collaboration as an explicit learning objective; collaboration with others through the discussion and implementation of design decisions; gaining new programming knowledge through hands-on experience via using Kodu; and experiencing more autonomous problem-solving and learning through overcoming gaps in knowledge. Students remained mostly engaged and on-task with the project over this period of weeks (timetabling clashes notwithstanding) and they produced a prototype interactive game using the Kodu software, showing that this was possible. We provided space to the teenagers in decision making so that they could express their view within both the design choices of the game and the internal organisation of the sessions. Such an approach helped to meet specific curriculum requirements in England regarding the teaching and learning of computer programming. Thus, there are positive benefits for participation and social 
inclusion, as well as for academic outcomes, even if in a very modest way in the context of a small-scale project like this.

Regarding collaboration strategy during the design process, both students preferred working with adults than with each other. Interestingly, similar behaviour was also observed with typically developing $5^{\text {th }}$ grade students who only shared ideas about the game objectives and then programmed the game individually (Baytak and Land, 2011). Nevertheless, in a different design context, Ruble and Robson (2007) observed that children with autism were more engaged in small group than in one-on-one interaction with an adult. Therefore, this behaviour may be more related to the nature of the tasks rather than membership of any particular diagnostic group. Moreover, personal friendships and individual preferences about who to work with, and how to work, are also parameters that should be taken into account.

Besides, even though their interactions with each other were limited, they did work together with the adults. On the one hand, programming in collaboration does not affect the children's learning process of the specific targeted concepts (Kwon and Cifuentes, 2009). Indeed, the students still showed valuable problem-solving, perseverance, and programming skills as has similarly been observed with typically developing children (Akcaoglu, 2014; Hwang et al., 2014; Ke, 2014). On the other hand, the exchange of knowledge between stakeholders might be an opportunity to improve the quality of the game prototype (Hwang et al., 2014). In this study, Nathan learnt through the adult's expertise how to use complex programming code and thus, he was able to generate several intelligent enemies to make the tutorial stage richer.

Overall, this study aims at exploring new spaces in which teenagers on the autism spectrum could feel more comfortable to design scenarios from their own perspective. This opens interesting questions to help researchers understand better how the strengths 
and preferences of people with autism could be more effectively represented and supported. For instance, Kodu programming software does facilitate students to demonstrate their interests, creativity and perseverance. However, we started from a particular position of aiming for an interactive game with specific collaborative features, albeit in a process where students were given quite a lot of freedom to design the game their own way. As a result, our objective sat in tension with the aspiration to adopt an open process with the students whereby they were encouraged to contribute their individual ideas. We assumed that the way we scaffolded and shaped the design process would enable the students to consider including social collaboration in their designs. Instead, they focused on the more technical aspects of collaboration and kept communication and interaction with others in the game limited in accordance with their own preferences.

This might suggest that it may not be possible to reconcile a process-focused approach to the design (supporting collaboration with each other) with an outcome-focused one (aiming to design-in collaboration through the game). Therefore, researchers might be less concerned about the potential learning outcomes of the games when the design process is more open, flexible and reciprocal (Parsons and Cobb, 2014). This study is of course small-scale and so generalisations cannot be drawn. Nevertheless, it provides insights into a design process to show what was possible and what was achieved. As such it might serve as starting point for further studies that involve teenagers with autism in the design and development of their own videogames.

One way to strengthen our approach would be to ensure that individuals on the autism spectrum are integrated more deeply in initiating and shaping the research agenda instead of simply being recipients or discussants of it (Parsons and Cobb, 2014; Pellicano et al., 2014). The ASCmeI.T. project (Parsons et al., 2016) is a good example that could be 
applied to game design, whereby members of the autism community are provided with a free app through which they can upload and share ideas on which kinds of technology need to be developed to better support individuals on the autism spectrum and their families. Studies with more participants would also allow a stronger analysis and understanding of the diversity of their own visions and preferences regarding how collaborative skills can be supported in games design. In larger-scale studies it would also be valuable to find out more about the hobbies and interests of participants so that we might understand better how these individual factors influence game design, potentially in important ways. It has also been observed that some students with autism may prefer teaming up with typically developing peers (Bauminger et al., 2003; Kasari et al., 2016). Consequently, it would also be interesting to organise sessions with mixed peer students and analyse the collaborative strategies they undertake. 


\section{References}

American Psychiatric Association. (2013). Diagnostic and statistical manual of mental disorders (5th ed.). Washington, DC: Author

Akcaoglu M. (2014). Learning problem-solving through making games at the game design and learning summer program. Journal of Educational Technology Research and Development, 62 (5), pp 583-600

Bauminger, N., Shulman, C., \& Agam, G. (2003). Peer interaction and loneliness in high functioning children with autism. Journal of Autism and Developmental Disorders, 33(5), 489-507.

Baytak, A., \& Land, S. M. (2011). An investigation of the artifacts and process of constructing computers games about environmental science in a fifth grade classroom. Journal of Educational Technology Research and Development, 59(6), pp. 765-782.

Benton L., Johnson H., Ashwin E., Brosnan M., Grawemeyer B. (2012). Developing IDEAS: Supporting children with autism within a participatory design team. In Proc. of CHI'12, pp. 2599-2608

Benton L., Johnson H. (2014). Structured approaches to participatory design for children: can targeting the needs of children with autism provide benefits for a broader child population? Journal of Instructional Science, 42, pp. 47-65

Benton, L. \& Johnson, H. (2015). Widening participation in technology design: a review of the involvement of children with special educational needs and disabilities. International Journal of Child-Computer Interaction, 3-4, 23-40

Bossavit B., Parsons S. (2016). "This is how I want to learn": High Functioning Autistic Teens Co-Designing a Serious Game. Proceedings of the 2016 CHI Conference on Human Factors in Computing Systems (CHI'16), 1294-1299

Bratteteig T., Wagner I. (2012). Disentangling power and decision-making in participatory design. Participatory Design Conference 
Chen, W. (2012).Multitouch Tabletop Technology for People with Autism Spectrum Disorder: A Review of the Literature. In Proc. of the International Conference on Software Development for Enhancing Accessibility and Fighting Info-exclusion. Procedia Computer Science, vol. 14, 2012, pp.198 - 207

Denner, J., Werner, L., \& Ortiz, E. (2012). Computer games created by middle school girls: Can they be used to measure understanding of computer science concepts? Journal of Computers \& Education, 58(1), pp. 240-249

Druin A. (2002). The role of children in the design of new technology. Behaviour and IT, 21(1), pp. 1-25

Dykstra Steinbrenner, J.R., Watson, L.R. (2015). Student Engagement in the Classroom: The Impact of Classroom, Teacher, and Student Factors. Journal of Autism and Developmental Disorders, 45 (8), pp. 2392-2410

Frauenberger, C., Good, J., \& Keay-Bright, W. (2011). Designing technology for children with special needs: bridging perspectives through participatory design. CoDesign, 7(1), 1-28.Fristoe, T., Denner, J., MacLaurin, M., Mateas, M, \& Wardrip-Fruin, N. (2011). Say it with Systems: expanding Kodu's expressive power through gender-inclusive mechanics. In Proc. of the international conference on the foundations of digital games, pp. 227-234.

Gee, J. P. (2003). What video games have to teach us about learning and literacy. New York: Palgrave Macmillan.

Giusti, L., Zancanaro, M., Gal, E. and Weiss, P. L. T. (2011) Dimensions of collaboration on a tabletop interface for children with autism spectrum disorder. In proc. of CHI'11, 3295-3304

Guha M.L., Druin A., Fails J.A. (2013) Cooperative Inquiry revisited: Reflections of the past and guidelines for the future of intergenerational co-design. International Journal of Child-Computer Interaction, 1(1), pp. 14-23.

Hwang. G.J., Hung. C.M., Chen N.S. (2014). Improving learning achievements, motivations and problem-solving skills through a peer assessment-based game 
development approach. Journal of Educational Technology Research and Development, 62 (2), pp 129-145.

Jordan, R. (2005). Autistic spectrum disorders. Chapter in B. Norwich and A. Lewis (Eds) (2005) Special teaching for special children?: pedagogies for inclusion. Maidenhead, England: McGraw-Hill International (pp.110-122).

Kafai, Y. B. (2006). Playing and making games for learning instructionist and constructionist perspectives for game studies. Games and Culture, 1(1), 36-40.

Kapp, K. M. (2012). The gamification of learning and instruction: Game-based methods and strategies for training and education. San Francisco, CA: Pfeifer

Kasari, C., Dean, M., Kretzmann, M., Shih, W., Orlich, F., Whitney, R., Landa, R., Lord, C., King, B. (2016). Children with autism spectrum disorder and social skills groups at school: a randomized trial comparing intervention approach and peer composition. Journal of Child Psychology and Psychiatry and Allied Disciplines, 57(2), 171-179

Ke, F. (2014). An implementation of design-based learning through creating educational computer games: A case study on mathematics learning during design and computing. Journal of Computers \& Education, 73(1), pp. 26-39.

Kenny, L., Hattersley, C., Molins, B., Buckley, C., Povey, C., Pellicano, E. (2016). Which terms should be used to describe autism? Perspective from the UK autism community. Autism, 20(4), 442-462

Kwon, S. Y., \& Cifuentes, L. (2009). The comparative effect of individual-constructed vs. collaboratively-constructed computer-based concept maps. Computers \& Education, $52,365-375$

Millen, L., Cobb, S., \& Patel, H. (2011). Participatory design approach with children with autism. International Journal on Disability and Human Development, 10(4), 289-294

National curriculum in (2013). https://www.gov.uk/government/publications/national-curriculum-in-englandcomputing-programmes-of-study. Accessed on February 2016 
Nouwen, M., Schepers, S., Mouws, K., Slegers, K., Kosten, N., \& Duysburgh, P. (2016). Designing an educational music game: What if children were calling the tune? International Journal of Child-Computer Interaction.

Parsons, S., Millen, L., Garib-Penna, S. \& Cobb, S. (2011) Participatory design in the development of innovative technologies for children and young people on the autism spectrum: the COSPATIAL project. Journal of Assistive Technologies, 5(1), 29-34.

Parsons S., Cobb S. (2014). Reflections on the role of the 'users': challenges in a multidisciplinary context of learner-centred design for children on the autism spectrum. International Journal of Research \& Method in Education, 37(4), pp. 421-441.

Parsons, S. (2015) Learning to work together: designing a multi-user virtual reality game for social collaboration and perspective-taking for children with autism. International Journal of Child-Computer Interaction, 6, pp. 28-38

Parsons S., Yuill N., Good J., Brosman M., Austin L., Singleton C., Bossavit B., Barnabear. What technology for autism needs to be invented? Idea generation from the autism community via the ASCmeI.T. app. In Proc. of ICCHP'16, pp343-350

Pellicano, E., Dinsmore, A., \& Charman, T. (2014). What should autism research focus upon? Community views and priorities from the United Kingdom. Autism, 18, 756-770

Ploog, B. O., Scharf, A., Nelson, D., \& Brooks, P. J. (2013). Use of computer-assisted technologies (CAT) to enhance social, communicative, and language development in children with autism spectrum disorders. Journal of Autism and Developmental Disorders, 43(2), 301-322

Ruble, L. A., \& Robson, D. M. (2007). Individual and environmental determinants of engagement in autism. Journal of Autism and Developmental Disorders, 37, 1457-1468

Silva, G.F.M., Raposo, A., Suplino, M. (2015). Exploring Collaboration Patterns in a Multitouch Game to Encourage Social Interaction and Collaboration Among Users with Autism Spectrum Disorder. Journal of Computer Supported Cooperative Work, 24(2), pp 149-175 
Vos, N., van der Meijden, H., \& Denessen, E. (2011). Effects of constructing versus playing an educational game on student motivation and deep learning strategy use. Journal of Computers \& Education, 56(1), pp. 127-137.

Wass S.V., Porayska-Pomsta K. (2014) The uses of cognitive training technologies in the treatment of autism spectrum disorders. Autism, 18(8), pp. 851-871 


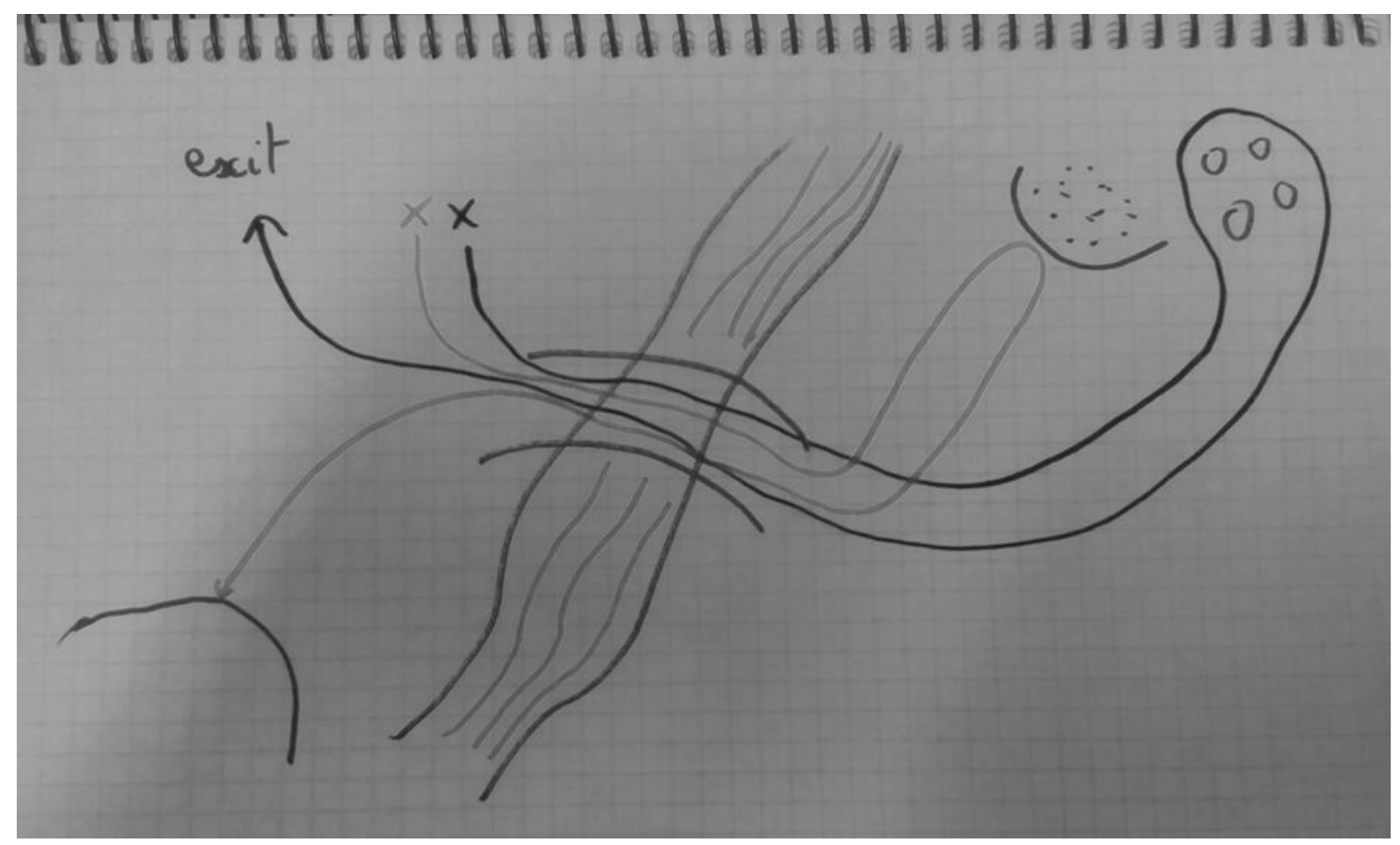

Figure1: The two players start at the same place. The warrior (in light grey) goes and distracts the enemies and attracts them to the opposite direction while the elemental character (in dark grey) goes for the coins and heads towards the exit. 


\section{Development}

\section{Session 1 \& 2: Programming}

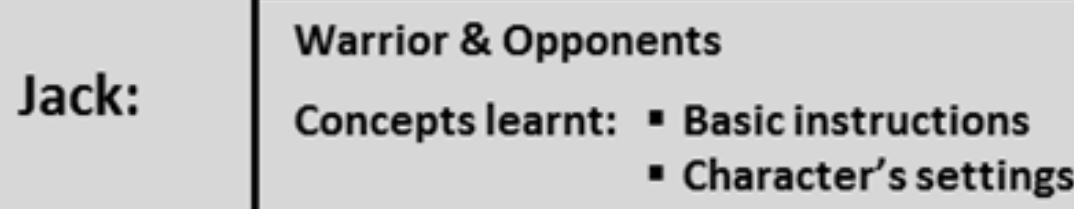

\section{Nathan: \\ Character who manipulates elements

$$
\begin{aligned}
\text { Concepts learnt: - Creatables } & \\
& \text { - Use of multi-pages }
\end{aligned}
$$

\section{Session 3: Merging}

Jack \& Nathan: Integration of Jack's code to Nathan's project $\longrightarrow$ Conflict with keyboard

Nathan: Decided which keys fit the best

Jack: Waited for sharing his character's settings

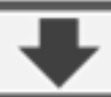

\section{Session 4: Testing \& Debugging}

\section{Issue: Warrior could kill his partner}

Nathan: Problem solved without adults' help

Figure 2: Description of development stage 


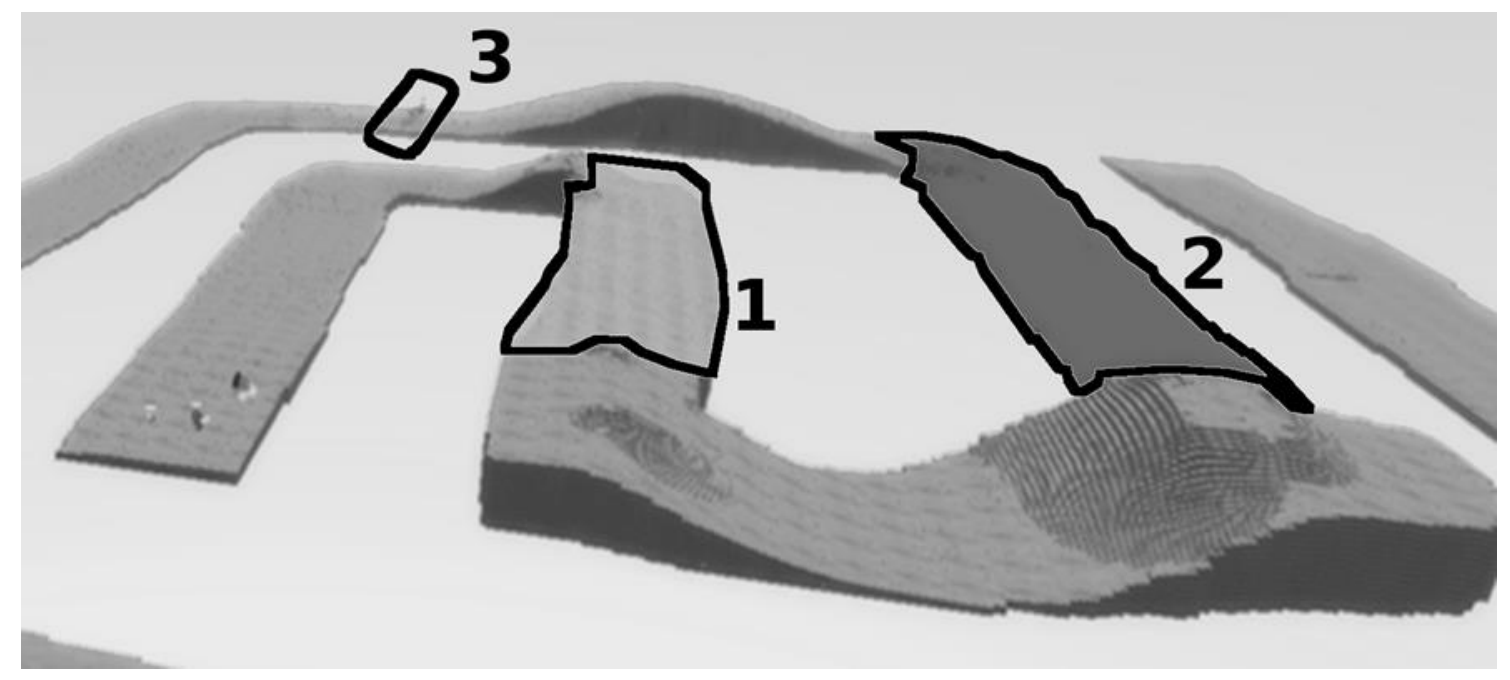

Figure 3: Screenshot of the tutorial level with the different enigmas such as water (1), lava (2) and a row of enemies (3) 
Table 1: Mapping for each session, teenager (pseudonyms) and adults

\begin{tabular}{|c|c|c|c|c|c|c|}
\hline \multirow{2}{*}{ Stage } & \multirow{2}{*}{ Participant } & \multicolumn{2}{|c|}{$\begin{array}{c}\text { Level of } \\
\text { participation }\end{array}$} & Tasks achievement & \multicolumn{2}{|c|}{ Stakeholders' role } \\
\hline & & $\underset{\text { (A) }}{\text { Participation }}$ & $\underset{\text { (A) }}{\text { Tool used }}$ & $\underset{\text { (B) }}{\text { Decision-made }}$ & $\underset{\text { (A) }}{\text { Role }}$ & $\begin{array}{l}\text { Power-sharing } \\
\text { (B) }\end{array}$ \\
\hline \multirow{4}{*}{$\begin{array}{c}1 . \\
\text { Introduction } \\
\text { to Kodu }\end{array}$} & Nathan & Dialogue & Tutorials & & User & - \\
\hline & Jack & Feedback & Tutorials & & User & - \\
\hline & Researcher & - & - & Types of exercises & Facilitator & $\begin{array}{l}\text { Values and } \\
\text { concepts }\end{array}$ \\
\hline & Teacher & - & - & Types of exercises & Facilitator & $\begin{array}{l}\text { Values and } \\
\text { concepts }\end{array}$ \\
\hline \multirow{3}{*}{$\begin{array}{l}2 . \\
\text { Game- } \\
\text { design }\end{array}$} & Nathan & Dialogue & $\begin{array}{l}\text { Internet / } \\
\text { Paper }\end{array}$ & Characters' features & Designer & $\begin{array}{l}\text { Values and } \\
\text { concepts }\end{array}$ \\
\hline & Jack & Dialogue & Sketching & Scenario & Designer & $\begin{array}{l}\text { Values and } \\
\text { concepts }\end{array}$ \\
\hline & Researcher & Dialogue & - & $\begin{array}{l}\text { Validation of } \\
\text { students' } \\
\text { propositions }\end{array}$ & Co-designer & $\begin{array}{l}\text { Values and } \\
\text { concepts }\end{array}$ \\
\hline \multirow{4}{*}{$\begin{array}{c}3 . \\
\text { Development }\end{array}$} & Nathan & Dialogue & Internet & Game features & $\begin{array}{l}\text { Designer / } \\
\text { Developer }\end{array}$ & Implementation \\
\hline & Jack & Feedback & - & Game features & $\begin{array}{l}\text { Designer / } \\
\text { Developer }\end{array}$ & Implementation \\
\hline & Researcher & Dialogue & Internet & Game features & $\begin{array}{c}\text { Facilitator / } \\
\text { Co-developer }\end{array}$ & Implementation \\
\hline & Teacher & Dialogue & Internet & Game features & $\begin{array}{c}\text { Facilitator / } \\
\text { Co-developer }\end{array}$ & Implementation \\
\hline \multirow{2}{*}{$\begin{array}{c}4 . \\
\text { Level-design }\end{array}$} & Nathan & Dialogue & - & $\begin{array}{c}\text { Game and } \\
\text { character's features }\end{array}$ & Designer & Implementation \\
\hline & Researcher & Dialogue & - & $\begin{array}{c}\text { Validation of the } \\
\text { features }\end{array}$ & Co-designer & Implementation \\
\hline
\end{tabular}

(A) Categories from Benton and Johnson (2015)

(B) Categories from Bratteteig and Wagner (2012) 